\title{
The effects of stimulus sequence on event related potentials: A comparison of visual and auditory sequences
}

\author{
KENNETH SQUIRES, SILVIA PETUCHOWSKI, CHRISTOPHER WICKENS, \\ and EMANUEL DONCHIN \\ The Cognitive Psychophysiology Laboratory, University of Illinois, Champaign, Illinois 61820
}

\begin{abstract}
The effect of stimulus sequence on the waveform of the scalp-recorded event-related potential (ERP) was studied in the auditory and visual modalities. The results indicate that the sequential effects are qualitatively similar in the two modalities; however, an interaction appeared between the modalities and the stimulus effects. The degree of sequential effect was a function of whether or not the stimulus eliciting the ERP was the counted (target) event. This finding is discussed in terms of an expectancy model, and the interaction is attributed to variations in short-term memory for past events as a function of the level of processing required for each.
\end{abstract}

Subjects tend to react to a series of random binary stimuli as if the series was constructed with sequential constraints. As Sheridan and Ferrell $(1974$, p. 37) state, "people readily adopt hypotheses about the nature and source of probabilistic data.... One of the most persistent tendencies is to attribute unwarranted sequential dependency and pattern to sequences of events." These presumed sequential dependencies readily affect behavior. Remington (1969), for example, has shown that the choice reaction time for binary auditory stimuli depends upon the specific sequence of preceding stimulus presentations. In fact, Remington's data, and similar data described by Falmange, Cohen, and Dwivedi (1975), suggest that the effective sequences are at least five items long. While Remington's work is unique in first dealing with the effects of relatively long sequences, it is consistent with much data on sequential dependencies evaluated over successive trials (Audley, 1973; Bertelson, 1961).

K. Squires, Wickens, N. Squires, and Donchin (1976) have shown that there is an effect of stimulus sequence even when the task is merely to count the occurrences of one auditory stimulus in a Bernoulli series. In that study, sequential dependencies were revealed through an analysis of the waveform of the scalp-recorded event-related potential (ERP) from the brain. A waveform measure proportional to the amplitude of the P300 component of the ERP

This research was supported by the Defense Advance Research Projects Agency, Office of Cybernetic Technology (Craig Fields, Program Manager), under Contract No. N-000-14-76-C-0002, monitored by the Office of Naval Research. The helpful comments of Jack Israel and Gregory McCarthy are appreciated. K. Squire's present address: Department of Medicine, University of California, Irvine, 101 City Drive South, Orange, California 92668. Address reprint requests to $\mathrm{E}$. Donchin. elicited on each trial was found to depend upon the specific sequence of preceding stimuli in a manner analogous to Remington's reaction time data. In order to account for those results, K. Squires et al. (1976) defined a variable, "expectancy," whose value on each trial correlated with the amplitude of the P300 component elicited on that trial; the more unexpected the stimulus, the larger the amplitude of the P300 it elicited. Expectancy was presumed to be a function of the a priori probability of the stimulus (Tueting, Sutton, \& Zubin, 1971), and to fluctuate from trial to trial as a function of the specific sequence of preceding stimuli. ${ }^{1}$

The purpose of the present study was to determine whether the sequential effect was a function of the logical structure of the task or was idiosyncratic to auditory sequences. For this purpose, subjects counted occurrences of one of two possible stimuli in analogous auditory and visual conditions. The auditory condition essentially replicated that used previously (K. Squires et al., 1976, in press). The critical data were obtained with the visual series. The absence of sequential dependencies in that condition would suggest that the sequential effect was specific to the auditory modality. In case a sequential effect was obtained for visual stimuli, it was of interest to determine whether it related to sequences of visual stimuli in the same way it related to sequences of auditory stimuli. In fact, certain differences were anticipated because the expectancy model depended to a considerable degree on the operation of a shortterm memory. It was assumed that the presentation of a particular stimulus increases the expectancy that the stimulus will be repeated, and to an extent that diminishes exponentially over succeeding trials. Since the durations of memories for auditory and visual events are apparently different (Neisser, 1967), 
systematic differences between the rates of decay for the short-term memory functions for the auditory and visual sequences were likely.

A second purpose of the study was to investigate the assertion that the $\mathrm{P} 300$ component is independent of the modality of stimulation (Donchin \& Cohen, 1967; Sutton, Braren, Zubin, \& John, 1965). While the P300 tends to show similar behavior for all types of stimuli, until recently little has been done to directly compare $\mathrm{P} 300$ components elicited by stimuli of different modalities using the same subjects in similar experimental procedures. Noteworthy is the report by N. Squires, Donchin, K. Squires, and Grossberg (1977), and two reports in which Simson, Vaughan, and Ritter (1976, in press) compare the scalp distributions of auditory and visual ERPs. Ruchkin and Sutton (1973) also demonstrate functional similarities between auditory and visual omitted and emitted potentials. The relationship between P300 and expectancy, however, provides a framework for comparing auditory and visual P300 components in a relatively more complex situation than in those studies. If P300 is indeed an endogenous component (Donchin, 1975; Sutton et al., 1965), its amplitude as a function of expectancy as well as its scalp distribution should be independent of stimulus modality.

\section{METHODS}

Seven adults (three females, four males), ranging in age from 20 to 32 years, participated in the study, each in one $2-h$ testing session.

The subject's task was to count one of two alternative stimuli in a series of stimuli presented at a rate of one stimulus every $1.6 \mathrm{sec}$. There were two such series, one auditory and one visual. In the auditory condition, the stimuli were 60 -msec tone bursts (including 10-msec rise-fall times) delivered via TDH-39 earphones. The stimulus intensity was $80 \mathrm{~dB}$ SPL against a continuous background of wideband noise at $55 \mathrm{~dB}$ SPL. The frequencies of the two tones were $1,100 \mathrm{~Hz}$ (henceforth labeled " $A$ ") and 1,000 Hz (labeled " $a$ "). On any trial, either tone could appear with equal probability. The higher pitched tones (A) were counted ("targets") and the count was reported following each block of 200 stimulus presentations.

The visual stimuli were $50-\mathrm{msec}$ flashes of light, subtending $6^{\circ}$ of visual angle. Flashes of two different hues were produced by filtering the light with colored overhead-projector filters. On half the stimulus presentations, the flash was blue (labeled " $V$ "'), while on the other half, the flash was orange (" $v$ "). The subjects counted the blue flashes. The luminance of these fields was $20 \mathrm{fL}$, measured with a Spectra brightness spotmeter.

It had been previously established that these pairs of stimuli yield equivalent choice reaction times and similar amplitude and latency P300 components (N. Squires, 1977, Experiment 2). This observation was verified with two subjects from the current experiment.

For each subject there were at least five repetitions of blocks of 200 trials in each condition, balanced within and across subjects.

The scalp EEG was recorded using Burden $\mathrm{Ag}-\mathrm{AgCl}$ electrodes affixed with collodion at $P_{2}, C_{2}$, and $F_{2}$, according to the 10-20 system, referred to linked mastoids, with a wrist ground. An additional electrode pair, one electrode situated above and one lateral to the right eye, served to record eye-blink and eyemovement potentials. Amplification was by Grass 7P122 amplifiers (time constant $2.5 \mathrm{sec}$ and upper half-amplitude cutoff at $30 \mathrm{~Hz}$ ). At each of the four channels, the electrical activity was sampled every $3 \mathrm{msec}$ for a total of $768 \mathrm{msec}$ beginning $100 \mathrm{msec}$ prior to stimuls onset and stored on digital tape for off-line analysis.

Stimulus selection, stimulus presentation and data collection were under the control of a PDP 11/40 computer (Donchin \& Heffley, 1975). Data analysis was performed using a Harris Slash 4 computer.

The data analysis followed the procedure described by $\mathbf{K}$. Squires et al. (1976), which was derived from Remington's (1969) procedure. The single-trial ERPs were sorted for averaging according to the stimulus presented on each trial and the specific sequence of preceding stimuli. "First-order" ERPs were based on all single trials on which a particular stimulus was presented, regardless of the preceding sequence. Thus, for each modality, there were 2 first-order ERPs; for example, for the auditory modality, there was 1 for stimulus $A$ and 1 for stimulus a. Second-order ERPs were constructed by sorting according to the stimulus presented and the immediately preceding stimulus; consequently there were 4 second-order ERPs for each modality (e.g., 2 for stimulus A: AA and $\mathrm{aA}$; and 2 for stimulus a: aa and $\mathrm{Aa}$ ). Likewise, there were 8 third-order ERPs for each modality, 4 ending with the presentation of each stimulus (e.g., AAA, aAA, AaA, aaA and aaa, $A a a, a A a, A A a), 16$ fourth-order ERPs for each modality, and 32 fifth-order ERPs for each modality. (See K. Squires et al., 1976, for more details.) Trials which were contaminated by eyemovement or blink potentials were not included in the average ERPs, but all stimulus presentations were considered in determining the stimulus sequences. After excluding those trials with eye-related artifacts, each fifth-order ERP was the average of 20 to 40 single trials.

\section{RESULTS}

The effect of the preceding sequence of tones on the auditory ERP is shown in Figure 1, where grand average ERPs (over all subjects) for sequences up to fifth order are presented. The ERPs elicited by tone A for each sequence are superimposed on ERPs elicited by tone a preceded by the analogous sequence. Thus, the two first-order ERPs are superimposed at the apex of the tree. The four secondorder ERPs are presented at the nodes of the first two limbs with AA and aA superimposed upon aa and $\mathrm{Aa}$, respectively, and similarly for longer sequences. It is evident that stimuli preceded by long runs of unlike stimuli (i.e., aaaaA and AAAAa) elicit large P300 components, while stimuli preceded by long runs of like stimuli (i.e., AAAAA and aaaaa) elicit, at best, a minute P300. The amplitude of P300 also varies systematically between these two extremes. These data are essentially identical to those reported by K. Squires et al. (1976).

The results for the visual condition are shown in Figure 2. It is evident that the waveform of the visual ERP is sensitive to the specific sequence of preceding stimuli in a manner similar to that of the auditory ERP. This suggests that the process underlying the P300 component is independent of stimulus modality.

The waveform variations shown in Figures 1 and 2 


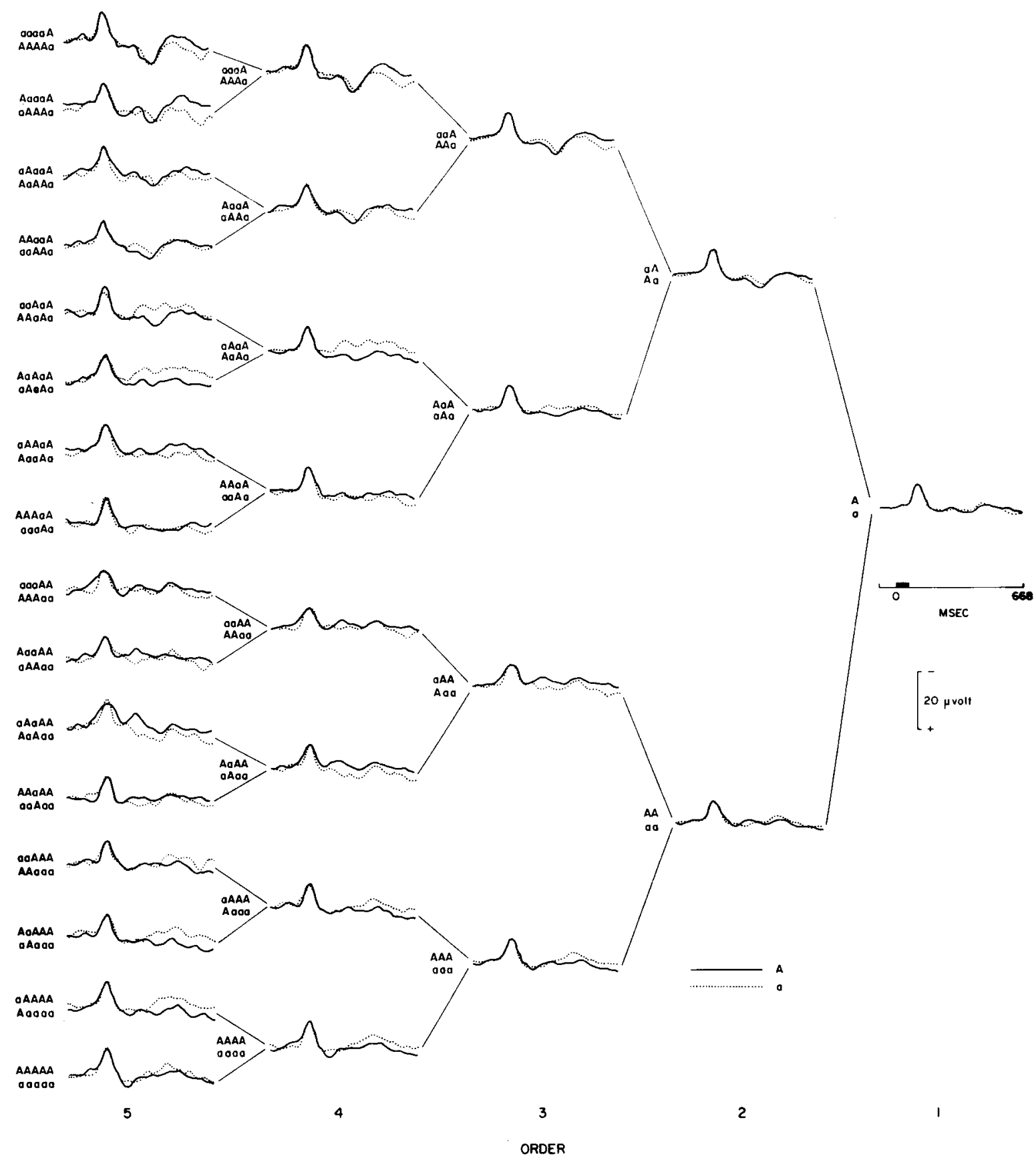

Figure 1. Averaged ERP waveforms (averaged across all subjects) for each sequence for auditory stimuli (data shown for $\mathrm{C}_{\mathrm{z}}$ electrode). Solid lines used for ERPs to target stimuli, dashed lines for nontarget stimuli.

were quantified using a stepwise discriminant analysis procedure (Donchin, 1969; Donchin \& Herning, 1975). Cross-subject discriminant functions were developed for the auditory and for the visual modality in a manner described by K. Squires et al. (1976) and K. Squires and Donchin (1976). Specifically, a discriminant function was developed from the single-trial ERPs of all subjects for each of the electrode sites which optimized the discrimination between the extreme fifth-order sequences for the counted stimulus in each modality (aaaaA vs. AAAAA and vvvvV vs. VVVVV). The ERPs for these sequences were considered representative of waveforms containing P300 components and waveforms which do not contain P300 components. The discriminant function provides weighting coefficients for the ERP amplitudes at six time points along the waveform, the first several points of which (those which best differentiate between the sets) sample the P300, N200, and slow-wave components of the ERP 


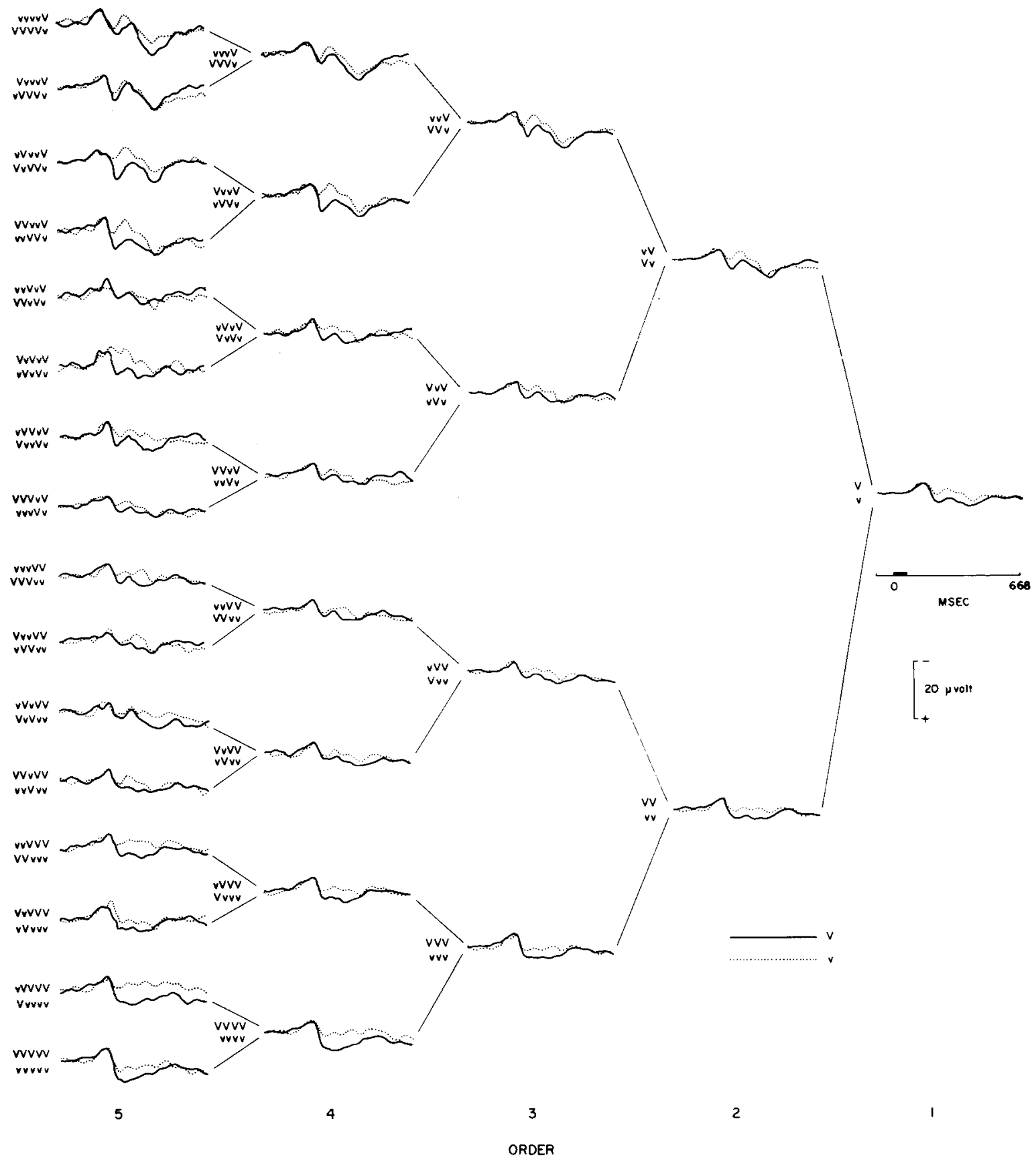

Figure 2. Same as Figure 1, for visual stimuli.

(K. Squires, Donchin, Herning, \& McCarthy, 1977; N. Squires, K. Squires, \& Hillyard, 1975). The latencies and weighting coefficients for the discriminant function are presented in Table 1. The group discriminant functions were applied to the data for each subject, and the resultant discriminant scores were averaged across electrodes, yielding a waveform statistic for each subject for each sequence. ${ }^{2}$
Plots of the mean discriminant statistics for each sequence in the two modalities are shown in Figures 3 and 4 . These tree structures are similar to those reported previously for the auditory modality alone (K. Squires et al., 1976). It is evident that similar relationships hold for the two modalities, thus supporting the conclusions drawn from the waveforms in Figures 1 and 2. 
Table 1

Latencies and Weighting Coefficients for the Group Discriminant Functions

\begin{tabular}{|c|c|c|c|c|c|c|}
\hline Electrode Site & $\mathrm{j}=1$ & $j=2$ & $j=3$ & $j=4$ & $\mathrm{j}=5$ & $j=6$ \\
\hline & \multicolumn{6}{|c|}{ Auditory Modality } \\
\hline $\begin{array}{c}\mathbf{P}_{z} \text { Latency, } \mathbf{i}(\mathrm{j}) \\
\text { Weight, a(j) }\end{array}$ & $\begin{array}{r}368 \\
.0069\end{array}$ & $\begin{array}{l}188 \\
-.0065\end{array}$ & $\begin{array}{l}248 \\
-.0048\end{array}$ & $\begin{array}{l}416.0040 \\
.0\end{array}$ & $\begin{array}{l}128 \\
-.0043\end{array}$ & $\begin{array}{l}56 \\
.0034\end{array}$ \\
\hline $\begin{array}{c}\mathrm{C}_{\mathrm{z}} \text { Latency, } \mathrm{i}(\mathrm{j}) \\
\text { Weight, a(j) }\end{array}$ & $\begin{array}{l}272 \\
-.0059\end{array}$ & $\begin{array}{r}368 \\
.0088\end{array}$ & $\begin{array}{l}188 \\
-00.71\end{array}$ & $\begin{array}{l}56 \\
00.93\end{array}$ & $\frac{32}{-.0062}$ & $\begin{array}{l}632 \\
-.0034\end{array}$ \\
\hline \multirow[t]{2}{*}{$\begin{array}{c}F_{z} \text { Latency, i(j) } \\
\text { Weight, a(j) }\end{array}$} & $\begin{array}{r}368.0074 \\
\quad .00\end{array}$ & $\begin{array}{r}632 \\
-.0074\end{array}$ & $\begin{array}{l}164 \\
-.0065\end{array}$ & $\begin{array}{r}440 \\
.0054\end{array}$ & $\begin{array}{l}200 \\
-.0053\end{array}$ & $\begin{array}{l}68 \\
.0040\end{array}$ \\
\hline & \multicolumn{6}{|c|}{ Visual Modality } \\
\hline $\begin{array}{l}P_{z} \begin{array}{l}\text { Latency, } i(j) \\
\text { Weight, a(j) }\end{array} \\
\text { (a) }\end{array}$ & $\begin{array}{r}404.0084 \\
\end{array}$ & $\begin{array}{l}296 \\
-.0058\end{array}$ & $\begin{array}{r}464 \\
.0041\end{array}$ & $\begin{array}{l}260 \\
-.0057\end{array}$ & $\begin{array}{l}356 \\
.0034\end{array}$ & $\begin{array}{r}586 \\
.0026\end{array}$ \\
\hline $\mathrm{C}_{\mathrm{z}} \begin{array}{c}\text { Latency, } \mathrm{i}(\mathrm{j}) \\
\text { Weight, a(j) }\end{array}$ & $\begin{array}{r}404 \\
.0074\end{array}$ & $\begin{array}{l}284 \\
-.0076\end{array}$ & $\begin{array}{l}464 \\
.0035\end{array}$ & $\begin{array}{l}644 \\
-.0037\end{array}$ & ${ }^{164} .0065$ & $\begin{array}{l}188 \\
-.0047\end{array}$ \\
\hline $\begin{array}{c}F_{z} \text { Latency, i(j) } \\
\text { Weight, a(j) }\end{array}$ & $\begin{array}{r}404 \\
.0070\end{array}$ & $\begin{array}{l}308 \\
-.0029\end{array}$ & $\begin{array}{l}644 \\
-.0028\end{array}$ & $\begin{array}{r}164 \\
.0034\end{array}$ & $\begin{array}{l}260 \\
-.0032\end{array}$ & $\begin{array}{r}72.0058\end{array}$ \\
\hline
\end{tabular}

Note-The latencies are referred to stimulus onset and the weighting coefficients are for voltages in arbitrary units referred to a baseline voltage over a 100-msec prestimulus interval. The equation for the discriminant function is:

$$
D F=\sum_{j=1,6} a_{j} X_{i(j)}
$$

where $X_{i(j)}$ is the voltage at latency $i(j)$ (in milliseconds) and $a_{j}$ is the weighting applied to that voltage value. The terms are presented in the order in which they were selected by the discriminant analysis procedure.
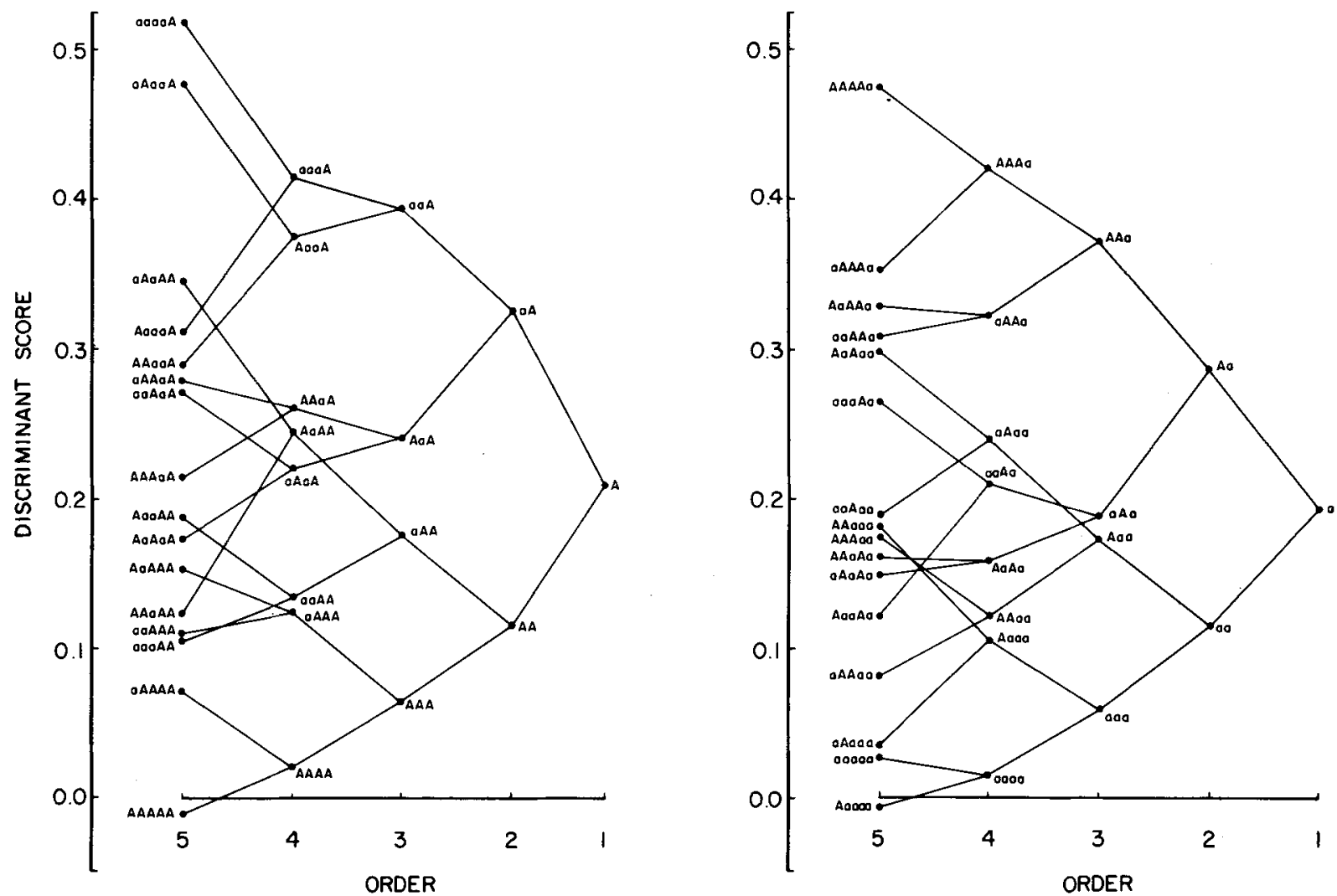

Figure 3. Plots of mean discriminant score statistics for the auditory stimuli. Data for target stimuli are on the left, for nontargets on the right. 

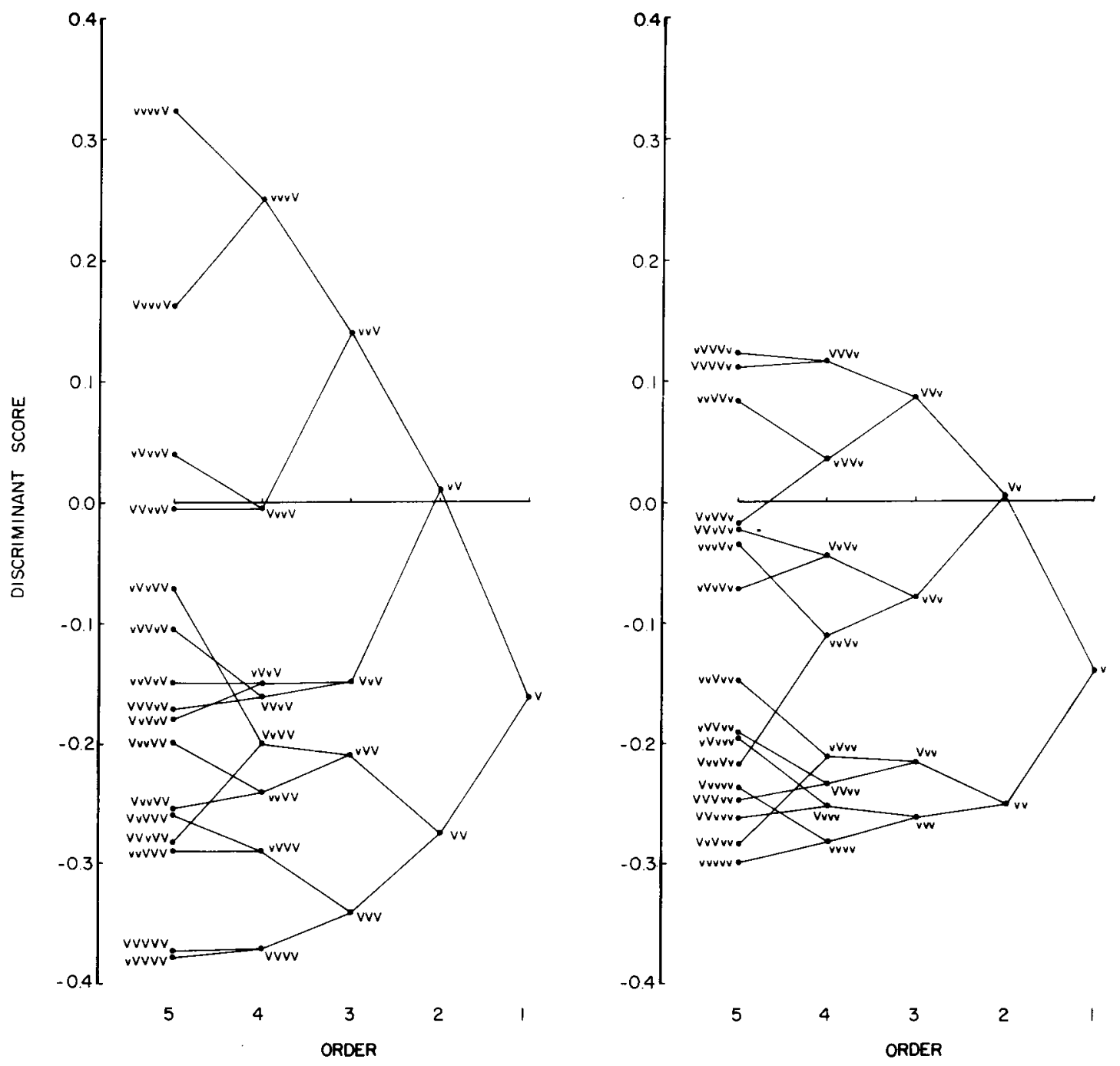

Figure 4. Same as Figure 3, for visual stimuli.

\section{Expectancy}

According to the previously derived model, the amplitude of the P300 (and associated N200 and slow-wave components) elicited by a given stimulus is inversely related to the extent to which the stimulus was expected. It was further assumed that expectancy is determined not only by the a priori probability that a stimulus will occur (Tueting et al., 1971; N. Squires et al., 1975), but also by the specific ordering of stimuli within the preceding sequence. The specific ordering of preceding stimuli affected expectancy through the operation of two independent components. These are: (a) a decaying memory component which provides that recent presentations of a given stimulus increases the expectancy that it will recur, but the influence of each presentation decays over trials, and (b) a term which accounts for the expectancies generated by sequences of alternat- ing stimuli (e.g., AaAa). The specific equation for the expectancy model was:

Expectancy $=0.235 \mathrm{M}+0.033 \mathrm{Alt}+0.505 \mathrm{P}+$ Const .

The memory term, $M$, yields an expectancy for event $\mathrm{A}$ on trial $\mathrm{N}$ as a function of the sequence of past events $S_{i}$,

$$
M=\sum_{i=N-1}^{N-5} \alpha^{N-i} S_{i},
$$

where

$$
S_{i}=\begin{aligned}
& 0 \text { for } S_{i}=a \\
& 1 \text { for } S_{i}=A
\end{aligned}
$$


and $\alpha$ corresponds to the rate of decay in memory of prior stimulus information. The best fit value for $\alpha$ was 0.6 . The alternation term, Alt, ranged from +3 to -3 and depended upon the number of prior alternations of stimuli. The Alt term proved necessary because subjects seem to expect that alternations, once begun, will continue. For details see K. Squires et al. (1976). The parameter $P$ is the a priori probability of stimulus $A$ in the sequence. In the present study, $\mathrm{P}=.5$. The parameters of the model were derived to fit the data, and the resultant equation accounted for $78 \%$ of the variance in the discrimination scores across fifth-order sequences $(r=-0.88)$.

A test of the similarity of sequential effects in the two modalities was performed by correlating the discriminant scores for this experiment with the expectancy values for each sequence previously derived for the auditory modality. As expected, the fifth-order discriminant scores for the $\mathrm{A}$ and $\mathrm{a}$ sequences were highly correlated with the predicted expectancies. The Pearson correlations were $r=$ -0.84 and $\mathrm{r}=-0.85$, respectively. For individual subjects, the correlations ranged from -0.30 to -0.88 (with a mean of -0.55 ) for $A$ sequences and from -0.44 to -0.73 (with a mean of -0.57 ) for a sequences. In the visual modality, the correlations for the $\mathrm{V}$ and $\mathrm{v}$ sequences were -0.86 and -0.66 , respectively. For individual subjects, the correlations ranged from -0.39 to -0.84 (with a mean of -0.68 ) for $\mathrm{V}$ sequences and from +0.05 to -0.71 (with a mean of -0.43 ) for $v$ sequences. Thus the model was as effective in accounting for the characteristics of new auditory data and of visual-target data as it was for the data upon which it was based. The model was, however, less successful in accounting for the data for visual nontarget stimuli.

Since the sequential effect was qualitatively similar across modalities, it was presumed that the relative weakness of the model in accounting for the data for visual nontargets might be due to variations in the parameters of the model rather than to its general form. The parameters were therefore rederived for the data for each stimulus in this experiment. For both of the auditory stimuli and for visual-target stimuli, the parameters were virtually identical to those derived by K. Squires et al. (1976). For visual nontarget stimuli, however, the memory term had a higher rate of decay $(\alpha=0.4)$ and sequences of alternations had insignificant effects on the expectancy score. The correlation between the discriminant scores for visual nontargets and the reformulated expectancy function for those stimuli was -0.89 . For individual subjects, the new correlations ranged from -0.28 to -0.83 (with a mean of -0.58 ). The correlation became more negative for every subject. It appears, then, that, while all stimuli in this experiment exhibit sequential effects, the nontarget flashes reflect a more transient dependence upon past presentations of stimuli than do the other three types of stimuli.

Additional data for evaluating the nature of the sequential effect is provided by the distribution of amplitudes over the scalp of the major ERP component, P300, associated with the effect. These distributions are shown in Figure 5. The amplitudes were measured for the fifth-order sequences, which generally yielded the largest P300 component for each stimulus, i.e., aaaaA, AAAAa, vvvvV, and VVVVv. In each case, the amplitude was referred to a 100-msec prestimulus baseline, and scaled in terms of the percentage of the largest amplitude P300 for each subject and stimulus modality. For auditory stimuli, the scalp distributions for the target and nontarget stimuli were essentially identical; the small amplitude difference was nonsignificant and there were significant parietal-to-frontal amplitude decreases for both stimuli $(p<.01)$. For visual targets, there was also a significant parietal-to-frontal decrease in amplitude resembling that for the auditory stimuli. The amplitudes for the nontarget visual stimuli, however, showed no significant change across the electrode array and were significantly smaller than for targets $(p<.05)$.

\section{DISCUSSION}

In this study, the probability that a given stimulus would be presented on any trial was independent of the stimuli presented on preceding trials, yet the waveform of the ERP elicited on any trial depended on the specific sequence of preceding stimuli. In a
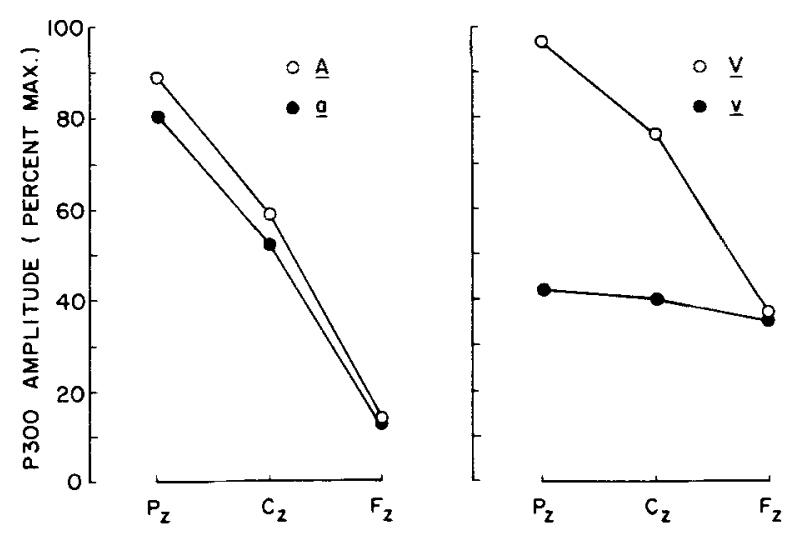

ELECTRODE SITE

Figure 5. Scalp distributions of the P300 component of the ERP. Amplitudes are referred to the voltage over the 100-msec prestimulus baseline. Left panel shows distribution for auditory stimuli, right panel for visual stimuli. 
previous study (K. Squires et al., 1976), it was hypothesized that these sequential effects could be attributed to trial-to-trial variations in the subjective probability (or expectancy) that each stimulus would occur. Accordingly, a model was developed which related expectancy to the combined effects of the a priori probability of the events, the operation of a memory for previous events, and the effect of the specific structure of the event sequences. At issue in the present study was the extent to which the rules found to govern the waveform of the ERP, and by inference the underlying expectancies, associated with sequences of auditory stimuli also held for visual sequences. The results showed no fundamental differences between the sequential effects in the two modalities.

While the sequential effects were qualitatively similar across modalities, an interesting interaction appears between the stimulus modality and the relative characteristics of the sequential effects for target and nontarget stimuli. For auditory stimuli, the sequential effects observed were identical for targets and nontargets, as evidenced by the fact that identical memory decay constants were found $(\alpha=0.6)$. For visual stimuli, the memory decay constant for target stimuli was also equal to 0.6 , the same as for the auditory stimuli; however, for nontarget stimuli, the decay rate was more rapid ( $\alpha=$ $0.4)$. This result suggests that the processing associated with each presentation of the nontarget stimulus was less influenced by previous presentations of that stimulus than was the case for the other three types of stimuli in this experiment. As the waveforms of the visual ERPs elicited by targets and nontargets are more clearly distinct than are the corresponding auditory ERP waveforms. It might be argued that it was inappropriate to use a discriminant function based on the visual targets to measure the ERPs elicited by the visual nontargets. The fact is, however, that the discriminant function we used does extract the orderly sequential relationships in the nontarget visual ERPs, and that our model, with a change in parameter, does successfully describe these data. Using a standard procedure for both modalities, we reveal a difference between auditory and visual ERPs, which variance is accounted for by a change in the "short-term memory" parameter of our model.

This interaction in sequential processing between stimulus modality and target class might be explained if the level of processing required by the counting operation transforms an event from a modalityspecific representation to a representation that is relatively independent of the modality. The expectancy for target stimuli is thereby based upon the relative frequency in the past of occurrences of target events whose rate of loss from memory is primarily a function, not of the modality of presentation, but of the level of processing required by the counting operation. On the other hand, when an event is not a target, it remains at a level of representation which is modality specific. The information about such stimuli is not transferred out of echoic or iconic memory (Neisser, 1967), and the expectancy for that event generated within the preceding sequences will reflect the temporal properties of these modalityspecific sensory memories. Numerous experimental findings confirm a more rapid decay rate for iconic than for echoic memory. Iconic memories appear to be retained little more than $1 \mathrm{sec}$ (e.g., Rummelhart, 1970; Sperling, 1960). This may be contrasted with estimates of the length of echoic memory which range from 2 to over $10 \mathrm{sec}$ (cf. Crowder, 1975; Ericksen \& Johnson, 1964; Massaro, 1970; Wickelgren, 1969). This modality difference is compatible with the present results; the inferred decay rate for past presentations of nontarget auditory stimuli was slower $(\alpha=.6)$ than it was for nontarget visual stimuli $(\alpha=.4)$. This explanation assumes that the counted and uncounted events are processed in parallel, which was explicitly assumed in the model presented by K. Squires et al. (1976). The expectancy for each stimuls depended only on the occurrence of that stimulus on preceding occasions in the series. It is now postulated that these parallel processes represent different levels of processing. These differences did not affect the sequential effects for the auditory series, but did affect the visual series.

Beyond the ordinal comparison of a faster decay rate inferred for visual vs. auditory sensory stimuli, it is of note that the quantitative estimate of the decay parameter $(\alpha=.6)$ in the equation:

$$
M=\sum_{i=N-1}^{N-5} \alpha^{N-i} S_{i},
$$

is in close agreement with the exponential rate derived by Wickelgren (1969) describing his data for the short-term memory for pitch, clearly an analog of the stimulus conditions in this experiment. ${ }^{3}$

In addition, the dominant component responsible for the ERP waveform variations, the P300 component, was found to have an amplitude distribution over the scalp which was nearly identical for target and nontarget auditory stimuli, suggesting a common neural generator for both. Moreover, the parieto-frontal amplitude gradient for the auditory stimuli approximated that for visual target stimuli, but was steeper than for the visual nontarget stimuli, as would be expected if the component reflected the level of processing rather than the modality of stimulus presentation. It is, of course, possible that interaction between the modality and the stimulus type depends essentially on the dis- 
criminability of the two stimulus pairs. Perhaps subjects could distinguish the colors earlier in the processing sequence, while they had to completely recognize the sounds. It appears unlikely, however, that modality differences in stimulus discriminability were responsible for the differences in the extent of sequential processing. The auditory stimuli employed by $\mathrm{K}$. Squires et al. (1976) were considerably more discriminable $(1,000$ vs. $1,500 \mathrm{~Hz})$ than those employed here $(1,000$ vs. $1,100 \mathrm{~Hz})$, yet the estimate of the parameter $\alpha$ in the two experiments was virtually identical. ${ }^{4}$

In conclusion, our data serve to confirm and extend our previous report (K. Squires et al., 1976), in which it was demonstrated that the ERP waveform varies from trial to trial as a function of the specific structure of the stimulus sequence. This appears to be the case whether the stimuli presented are visual or auditory, supporting the view that $\mathrm{P} 300$ is an endogenous brain response (Donchin, 1975; Sutton et al., 1965) which is modality independent.

\section{REFERENCES}

Audley, R. Some observations on theories of choice reaction time: Tutorial review. In S. Kornblum (Ed.), Attention and performance IV. New York: Academic Press, 1973.

BERTELSON, P. Sequential redundancy and speed in serial twochoice responding task. Quarterly Journal of Experimental Psychology, 1961, 12, 90-102.

CRowDer, R. Inferential problems in echoic memory. In P. Rabbitt \& S. Dornic (Eds.), Attention and performance $V$. New York: Academic Press, 1975.

DoNCHIN, E. Data analysis techniques in average evoked potential research. In E. Donchin \& D. Lindsley (Eds.), Average evoked potentials-Methods, results and evaluations (NASA SP-191). Washington, D.C: Government Printing Office, 1969.

Donchin, E. Brain electrical correlates of pattern recognition. In G. Inbar (Ed.), Signal analysis and pattern recognition in biomedical engineering. New York: Wiley, 1975.

Donchin, E., \& CoHEN, L. Average evoked potentials and intra-modality selective attention. Electroencephalography and Clinical Neurophysiology, 1967, 22, 537-546.

Donchin, E., \& Heffley, E. Minicomputers in the signal averaging laboratory. American Psychologist, 1975, 30, 299-312.

Donchin, E., \& Herning, R. I. A simulation study of the efficacy of stepwise discriminant analysis in the detection and comparison of event related potentials. Electroencephalography and Clinical Neurophysiology, 1975, 38, 51-68.

Duncan-Johnson, C., \& Donchin, E. On quantifying surprise: The variation of event-related potentials with subjective probability. Psychophysiology, in press.

ERIKSEN, C., \& Johnson, H. Storage and decay characteristics of nonattended auditory stimuli. Journal of Experimental Psychology, 1964, 48, 28-36.

Falmange, J., Cohen, S., \& Dwivedi, A. Two-choice reactions as an ordered memory scanning process. In P. Rabbitt \& S. Dornic (Eds.), Attention and performance V. New York: Academic Press, 1975.

MASSARO, D. Retroactive interference in short-term recognition memory for pitch. Journal of Experimental Psychology, 1970, 83, 32-39.

NeISSER, U. Cognitive psychology. New York: Appleton-CenturyCrofts, 1967.
Remington, R. Analysis of sequential effects in choice reaction times. Journal of Experimental Psychology, 1969, 2, 250-257.

Ruchkin, D., \& Sutton, S. Visual evoked and emitted potentials and stimulus significance. Bulletin of the Psychonomic Society, 1973, 2. 144.146.

RUMmelhaRT, D. A multi-component theory of the perception of briefly exposed visual displays. Journal of Mathematical Psychology, 1970, 7, 191-218.

Sheridan, T. B., \& FerRell, W. R. Man-machine systems: Information, control, and decision models of human performance. Cambridge, Mass: MIT Press, 1974.

SPERLING, G. The information available in brief visual presentations. Psychological Monographs, 1960, 11 (Whole No. 498).

Simson, R., Vaughan, H., \& RitTer, W. The scalp topography of potentials associated with missing visual or auditory stimuli. Electroencephalography and Clinical Neurophysiology, 1976, 40, 33.42.

Simson, R., Vaughan, H., \& RitTer, W. The scalp topography of potentials in auditory and visual discrimination tasks. Electroencephalography and Clinical Neurophysiology, in press.

Squires, K., \& Donchin, E. Beyond averaging: The use of discriminant functions to recognize event related potentials elicited by single auditory stimuli. Electroencephalography and Clinical Neurophysiology, 1976, 41, 449-459.

Souires, K., Donchin, E., Herning, R., \& McCarthy, G. On the influence of task relevance and stimulus probability on event-related-potential components. Electroencephalography and Clinical Neurophysiology, 1977, 42, 1-14.

Squires, K., Wickens, C., Squires, N., \& Donchin, E. The effect of stimulus sequence on the waveform of the cortical event-related potential. Science, 1976, 193, 1142-1145.

Souires, K., Wickens, C., Soutres, N., \& Donchin, E. Sequential dependencies of the waveform of the event-related potential: A preliminary report. In D. Otto (Ed.), Proceedings of the Fourth International Congress on Event Related Potentials. Washington, D.C: Government Printing Office, in press.

Soutres, N., Donchin, E., Soutres, K., \& Grossberg, S. Bisensory stimulation: Inferring decision-related processes from the P300 component. Journal of Experimental Psychology, 1977, 3, 299-315.

Squires, N., Squires, K., \& Hillyard, S. Two varieties of longlatency positive waves evoked by unpredictable auditory stimuli in man. Electroencephalography and Clinical Neurophysiology, 1975, 38, 387-401.

Sutton, S., Braren, M., Zubin, J., \& John, E. R. Evoked potential correlates of stimulus uncertainty. Science, 1965, 150, $1187-1188$.

Tueting, P., Sutton, S., \& Zubin, J. Quantitative evoked potential correlates of the probability of events. Psychophysiology, 1971, 7, 385-394.

WiCkelgren, W. Context-sensitive coding, associative memory, and serial order in (speech) behavior. Psychological Review, $1969,76,1-15$.

\section{NOTES}

1. The additivity of the effects of a prior probability and sequence structure has been corroborated by Duncan-Johnson and Donchin (in press).

2. It is not strictly necessary to use the discriminant score statistic to demonstrate the effects reported here; similar results were found plotting P300 amplitudes relative to the prestimulus baseline. While the results found using P300 amplitudes and discriminant scores are equivalent in all important respects, the discriminant score utilizes more waveform information than does the amplitude of one peak and, consequently, is less susceptible to residual EEG noise remaining in the averaged ERP waveform.

3. Wickelgren measured the probability of correct recognition of a presented tone pitch as a function of retention intervals 
(ranging from 0.5 to $4.0 \mathrm{sec}$ ). Wickelgren fit an exponential decay function of the form $M(t)=e^{-\lambda t}$ to the data, and the average value of $\lambda$ across six subjects was found to be 0.32 . In the current experiment, the exponential decay rate of the memory function was expressed in the form, $M(i)=\alpha^{i}$, that is, decay as a function of event number rather than time (a hypothesis yet to be tested). The latter expression was transformed to an exponential time-decay expression corresponding to Wickelgren's: $\left(\alpha^{t / 1.5}=\right.$ $\left.\mathrm{e}^{-\lambda t}\right)$. The derived value of $\lambda$ for the data in the present experiment, corresponding to $\alpha=.6$, was 0.36 -in close agreement with Wickelgren.
4. It will be noted that the argument made here does not depend on an assumed subjective equivalence, across modalities, of the intramodality difference. It is possible that the difference between 1,000 and $1,100 \mathrm{~Hz}$ is greater, or smaller, than the difference between the violet and the orange flashes. Nevertheless, the expectancy model adequately described the orderly sequential effects within the modalities, even for the visual nontargets, albeit with a different numerical value for the coefficient.

(Received for publication January 14, 1977; revision accepted April 1, 1977.) 